\title{
Alterations in cytokine measurements in ascitic fluid of cirrhotic patients with and without spontaneous bacterial peritonitis
}

\author{
Maria Lagadinou ${ }^{1 *}$, E.E Solomou ${ }^{1}$, A. Mouzaki ${ }^{2}$ and C.A. Gogos ${ }^{1}$ \\ *Correspondence: m_lagad2004@yahoo.gr

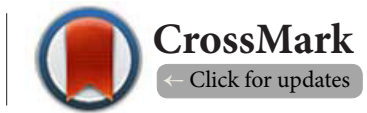 \\ 'Department of Internal Medicine, Patras University Hospital, Rio 46500, Greece. \\ ${ }^{2}$ Department of Hematology, Patras University Hospital, Rio 46500, Greece.
}

\begin{abstract}
$\underline{\text { Aim: }}$ To determine the pattern of cytokine synthesis in the ascitic fluid (AF) of cirrhotic patients, with or without spontaneous bacterial peritonitis (SBP).

Patients and methods: We prospectively studied 13 cirrhotic patients with ascites, who were admitted at the University Hospital of Patras from May 2008 to December 2009. Patients were separated into two groups: (a) group 1: patients SBP (n=7) (b) group 2: patients without SBP $(n=6)$. Cirrhosis was diagnosed on the basis of typical clinical, laboratory, ultrasonographic findings and/ or liver biopsy. Upon admission a paracentesis of ascetic fluid was performed. Ascitic levels of IL- 1b, IL-1ra, IL-6, IL- 10, TNFa, sTNFRI and sTNFRII were measured by using an ELISA method. Data are presented as absolute numbers (mean \pm standard deviation) and were compared using t test. A P value $<0.05$ was considered significant.

Results: Most patients, who were prospectively included in this study and were admitted to the hospital, were males and had cirrhosis due to alcohol abuse. The second cause of cirrhosis in this population was virus hepatitis ( $B, C$ or both). The middle age was $69 \pm 12$ years and $62 \pm 15$ years for Group 1 and Group 2 respectively. Multivariate analysis of proinflammator and antiinflammatory cytokines showed significant $(\mathrm{P}<0.05)$ differences in the levels of sTNFRII and IL-1ra between the two groups of patients (group 1: cirrhotics with SBP vs group 2: cirrhotics without SBP). Ascitic levels of IL-10, IL-6, IL-1ra, TNF-a, STNFRII and STNFRI were higher in ascitic fluid of patients with bacterial ascites, while TGF-b1 levels were lower in the ascitic fluid of patients with SBP (differences not significant). It is remarkable that IL-1b was not expressed in patients either with or without spontaneous bacterial peritonitis SBP.

Conclusions: We demonstrated an increased cytokine production in ascitic fluid of cirrhotic patients with SBP, while the levels of anti-inflammatory cytokines sTNFRII and IL-1ra are significantly increased in SBP. It seems, therefore, that an ascitic fluid antiinflammatory response is characteristic in SBP, and this might compromise the final outcome.
\end{abstract}

Keywords: Liver cirrhosis, cytokines, spontaneous bacterial infection, paracentesis

\section{Introduction}

There is increasingly evidence that several cytokines mediate hepatic inflammation, apoptosis and necrosis of liver cells, chollestasis and fibrosis. Interestingly, the same mediators also mediate the regeneration of liver tissue after injury [1]. Many immune system abnormalities have been associated with cirrhosis [2]. Most acute and chronic liver diseases are characterized by inflammation processes with enhanced expression of various pro- and anti- inflammatory cytokines in the liver [3]. Cytokines, in general, play an important role in host defense mechanism, and it is only under certain conditions that they may mediate deleterious results and contribute to the manifestations of tissue injury [4].

Spontaneous bacterial peritonitis (SBP) is an infectious disease specific to liver cirrhosis patients. Because inflammatory and immune reactions are altered by hepatic cirrhosis, the efficacy of innate reactions is limited [5]. SBP is associated with an important production of inflammatory mediators [6].
In these patients cytokines are released to blood and ascites, in response to hepatic injury [5].

The immunology of ascitic fluid is of interest to many investigators. In SBP, however, the immune system has not been studied in sufficient detail to determine the exact role of the humoral or cellular immune system. In the present study, we measured the ascitic fluid levels of IL- 1 b, TNF-a, IL-6, TGF$1 \mathrm{~b}$ and of their antagonists: IL-10, IL-1 ra, STNFRI and STNFRII. The aim of our trial was to determine the pattern of cytokine expression in the ascitic fluid (AF) of cirrhotic patients either with or without spontaneous bacterial peritonitis and investigate the effects of SBP on some cytokines in ascitic fluid.

\section{Patients and methods}

We prospectively studied 13 cirrhotic patients, who were admitted to the Department of Internal Medicine of University Hospital of Patras during the period from May 2008 until December 2009 , through a variety of reasons. From the amount of patients, 
seven patients developed SBP (group 1) and six patients presented no evidence of infection, including SBP (group 2). Cirrhosis was diagnosed on the basis of typical clinical (splenomegaly, hepatomegaly, ascites), laboratory (enhanced liver enzymes, prolonged prothrombine time), ultrasonographic findings and/or liver biopsy. The diagnosis of SBP was established by the presence of a polymorphonuclear cell count in ascitic fluid greater than 250 cells $/ \mathrm{mm}$, in the absence of clinical, radiological or laboratory data suggesting secondary peritonitis, hemorrhagic ascites, pancreatitis, mycobacterial or fungal peritonitis or carcinomatosis. We also observed indicators of inflammation: elevated leucocytes and CRP.

Exclusion criteria were the following: (a) clinical evidence of infection, except SBP (b) treatments which could modify the determination of cytokines (pentoxyfilline, steroidal or nonsteroidal anti-inflammatory or immunosuppressive drugs) (c) antibiotic treatment during the week before admission.

\section{Laboratory procedures- methods}

Ascitic fluid (AF) and serum samples from patients included in this study were prospectively collected. Upon admission, a paracentisis was performed using a standard sterile technique in all patients with ascites. Within 30 minutes the specimen obtained was centrifuged for 15 minutes and stored at $-70^{\circ} \mathrm{C}$ until analysis was performed. Also, blood samples were collected under sterile conditions and centrifused. Serum was collected and stored at $-70^{\circ} \mathrm{C}$.

Ascitic and serum levels of IL-1b, TNF-a, IL-6, IL-10, IL-1RA,
STNFRI and STNFRII were assayed with ELISA (kits from Diaclone, Besanco, France).

\section{Statistical analysis}

Data were presented as mean \pm standard deviation (SD). The data from two independent groups were compared using $t$ test. A P value $<0.05$ was considered statistical significant.

\section{Results}

\section{Characteristics of study population}

Characteristics of patients with Spontaneous Bacterial Peritonitis (SBP) (group 1) and without Spontaneous Bacterial Peritonitis (group 2) are provided in Table 1.

Most patients, who were prospectively included in this study and were admitted to the hospital, were cirrhotic because of alcohol abuse. The second cause of cirrhosis in this population was virus hepatitis (B, C or both). Group 1 patients as well as Group 2 patients were middle aged, which means 60-70 years old.

\section{Ascitic fluid concentrations of proinflammatory and anti-inflammatory cytokines \\ The ascitic concentrations of individual cytokines are shown in Table 2. Multivariate analysis showed significant differences $(P<0.05)$ between the two groups to the levels of STNFRII and IL-1RA. Ascitic levels of IL-10, IL-6, IL-1RA, TNF-a, STNFRII and STNFRI were higher (not statistical significant) in the ascitic fluid of patients with SBP. However, TGF-b1 levels were}

Table 1. Characteristics of patients. In this table we represent demographic characteristics and etiology of cirrhosis of the thirteen (13) cirrhotic patients with ascites who were studied.

\begin{tabular}{lll}
\hline Parameter & $\begin{array}{l}\text { Cirrhotic patient } \\
\text { with SBP }\end{array}$ & $\begin{array}{l}\text { Cirrhotic patients } \\
\text { without SBP }\end{array}$ \\
\hline Age (years) & $69 \pm 12$ & $62 \pm 15$ \\
Male:Female ratio & $5: 2$ & $5: 1$ \\
\hline Etiology of cirrhosis & & \\
\hline Ethanol & 5 & 4 \\
Virologic & 1 & 2 \\
Cryptogenic & 1 & -- \\
Others & -- & -- \\
\hline
\end{tabular}

Table 2. Cytokines absolute numbers represented per group. The table shows the measurements of cytokines' concentrations in ascitic fluid of thirteen cirrhotic patients, with ascites, who were admitted to hospital and were included in the study. We compared the absolute numbers of cytokines in ascitic fluid between patients with spontaneous bacterial peritonitis (group 1) and those without spontaneous bacterial peritonitis (group 2). All numbers represented are absolute numbers of cytokines.

\begin{tabular}{lllllllll}
\hline & IL-10 & TNF-a & STNFRI & STNFRII & IL-6 & IL-1B & IL-1RA & TGF-b1 \\
\hline Group 1 & $160 \pm 142$ & $11 \pm 20$ & $8191 \pm 3077$ & $5259 \pm 2354$ & $2413 \pm 3183$ & 0 & $946 \pm 703$ & $279 \pm 681$ \\
& & & & $P<0.05$ & & & $P<0.05$ & \\
Group 2 & $80 \pm 74$ & $0.5 \pm 1$ & $5618 \pm 2384$ & $2883 \pm 932$ & $2257 \pm 2478$ & 0 & $131 \pm 84$ & $378 \pm 671$
\end{tabular}

Furthermore: IL-10: interleukin 10 concentration, TNF-a: tumor necrosis factor a concentraion, STNFRI and STNFRII: soluble receptors' of TNF-a I and II concentrations, IL-6: interleukin 6 concentration, IL-1B: interleukin 1B concentration, IL-1RA: interleukin-1 receprors' concentration, TGF-1B: Tumor growth factor $1 \mathrm{~B}$ concentration. 
lower in group 1 patients. It is remarkable that IL-1b was not expressed in patients either with or without spontaneous bacterial peritonitis.

\section{Discussion}

The present study assesed the cytokines expression in ascitic fluid of cirrhotic patients with and without SBP. We compared the absolute numbers of proinfalammatory and anti-inflammatory cytokines between cirrhotic patients with ascites complicated with SBP and those without bacterial ascites. We analyzed ascitic fluid and serum concentrations of TNF-a, IL-1b, IL-10, IL-6, IL-1 ra, STNFRI, STNFRII and TGF-b1.

The main finding of the study, was that infection in the abdomen in patients with cirrhosis may enhance the expression of cytokines and their receptors as demonstrated by the significant increase in the absolute numbers of cytokines' levels measured in ascitic fluid. Higher levels of IL-10, TNF-a, STNFRI, STNFRII, IL- 6 and IL-1 ra were detected in the ascitic fluid of patients with SBP in comparison with patients without SBP. Similar findings have been reported in various clinical settings. A number of deficienies in the host immune defense system have been recognised in cirrhotic patients with SBP. Human studies in patients with cirrhosis and positive ascitic bacterial culture, have shown that cytokines of Th1 immune response are increased $[\mathbf{2}, \mathbf{4}, \mathbf{7}, \mathbf{8}]$.

Spontaneous ascites infection is a serious complication of cirrhosis and has a high mortality rate unless diagnosed and treated early [8]. Patients who develop SBP may have serum and ascitic fluid characteristics that are different from those who do not develop infection [8]. SBP is associated with a new increase in proinflammatory cytokines who could be antagonist by the concomitant elevation of several antiinflammatory agents [9]. IL-6, a macrophage derived cytokine [10-13], has been identified as an important mediator of the synthesis of acute phase reactants and this cytokine also plays a possible role in regulating TNF action. Another view is that IL- 6 is a counter-regulatory, anti-inflammatory cytokine of the pro-inflammatory cytokine TNF-a $[4,10]$. Our study showed that IL- 6 is produced within the peritoneal cavity in hepatic ascites and that there is a sharp increase in the local production during an episode of bacterial peritonitis $[11,13,14]$. All these suggest that IL-6 might participate in inflammatory action $[4,10]$. Although we found differences in the level of AF IL- 6 between the group 1 and group 2 patients, none of the differences were statistically significant.

No expression of IL-1b in all cirrhotic patients either with or without spontaneous bacterial peritonitis was observed.

Compared to cirrhotic patients with ascites but no SBP, patients with SBP showed statistical significant increased concentrations of STNFRII and IL-1RA $(P<0.05)$. Interesingly, high levels of IL-1RA and STNFRII can down regulate pathogen induced inflammatory responses by reducing cytokine secretion (Claudio Rodriguez-Ramos et al., 2001). It is notable that levels of STNFRII and IL-1RA were statistical significant increased, providing a putative mechanism to counteract deleterious effects caused by TNF-a [9].

From our observation in 13 patients, except AF IL-6, also TNF-a levels were shown to increase after SBP [15]. TNF-a is a macrophage derived cytokine, produced in large amounts in response to endotoxin. High AF levels of this cytokine have been observed in our patients with SBP $[11,16,17]$. Since SBP is considered to be the consequence of repeated episodes of bacteremia following intestinal bacterial translocation with seeding of $A F$, it might be considered that the intermittent presence of bacteria in blood may be followed by an activation of the cytokine cascade [11]. None of the differences was statistical significant.

Also, increased serum concentrations of IL-10 were detected in patients with SBP. IL-10 is another anti-inflammatory cytokine of Th2 immune response, regulating the extent of inflammation and the production of inflammatory cytokines [5]. IL-10 seem to act as a proviral agent thereby limiting its clinical utility [3]. IL-10 may suppress TNF-a activity by an inhibition of TNF-a secretion and down regulation of the expression of surface TNFRs $[\mathbf{9}, \mathbf{1 8}]$.

Our study suggested that elevated cytokines concentrations in ascites could perpetuate an inflammatory reaction that may be a source of preservation of an ongoing systemic inflammatory reaction [8]. Futhermore, the balance between pro-inflammatory and anti-inflammatory compounds could be implicated in the evolution of infection. Our study also showed elevated levels of anti-inflammatory molecules in those patients with bacterial ascites and elevated proinflammatory molecules. That could be interpreted as a mechanism of protection in those patients with the higher levels of pro-inflammatory compounds $[19,20]$.

\section{Competing interests}

The authors declare that they have no competing interests.

Authors' contributions

\begin{tabular}{|l|c|c|c|c|}
\hline Authors' contributions & ML & EES & AM & CAG \\
\hline Research concept and design & -- & -- & -- & $\checkmark$ \\
\hline Collection and/or assembly of data & $\checkmark$ & -- & -- & -- \\
\hline Data analysis and interpretation & $\checkmark$ & -- & $\checkmark$ & -- \\
\hline Writing the article & $\checkmark$ & $\checkmark$ & -- & $\checkmark$ \\
\hline Critical revision of the article & -- & $\checkmark$ & -- & $\checkmark$ \\
\hline Final approval of article & -- & -- & -- & -- \\
\hline Statistical analysis & $\checkmark$ & -- & -- & -- \\
\hline
\end{tabular}

\section{Publication history}

Editor: Somchai Amornyotin, Mahidol University, Thailand. Received: 04-Nov-2013 Revised: 13-Nov-2013 Accepted: 08-Feb-2014 Published: 24-Feb-2014

\section{References}

1. Tilg H. Cytokines and liver diseases. Can J Gastroenterol. 2001; 15:661-8. | Article | PubMed 
2. Albillos A, Hera Ad Ade L, Reyes E, Monserrat J, Munoz L, Nieto M, Prieto A, Sanz E and Alvarez-Mon M. Tumour necrosis factor-alpha expression by activated monocytes and altered T-cell homeostasis in ascitic alcoholic cirrhosis: amelioration with norfloxacin. J Hepatol. 2004; 40:624-31. | Article | PubMed

3. Tilg $\mathrm{H}$, Kaser A and Moschen AR. How to modulate inflammatory cytokines in liver diseases. Liver Int. 2006; 26:1029-39. | Article | PubMed

4. Zhang W, Yue B, Wang GQ and Lu SL. Serum and ascites levels of macrophage migration inhibitory factor, TNF-alpha and IL-6 in patients with chronic virus hepatitis B and hepatitis cirrhosis. Hepatobiliary Pancreat Dis Int. 2002; 1:577-80. I PubMed

5. Kim JK, Chon CY, Kim JH, Kim YJ, Cho JH, Bang SM, Ahn SH, Han KH and Moon YM. Changes in serum and ascitic monocyte chemotactic protein-1 (MCP-1) and IL-10 levels in cirrhotic patients with spontaneous bacterial peritonitis. J Interferon Cytokine Res. 2007 27:227-30. I Article I PubMed

6. Navasa M, Follo A, Filella X, Jimenez W, Francitorra A, Planas R, Rimola $A$, Arroyo $V$ and Rodes J. Tumor necrosis factor and interleukin- 6 in spontaneous bacterial peritonitis in cirrhosis: relationship with the development of renal impairment and mortality. Hepatology. 1998; 27:1227-32. | Article | PubMed

7. Ilonen I, Koivusalo AM, Repo H, Hockerstedt $\mathrm{K}$ and Isoniemi H. Cytokine profiles in acute liver failure treated with albumin dialysis. Artif Organs. 2008; 32:52-60. | Article | PubMed

8. Kiyici M, Nak SG, Budak F, Gurel S, Oral B, Dolar E and Gulten M. Lymphocyte subsets and cytokines in ascitic fluid of decompensated cirrhotic patients with and without spontaneous ascites infection. J Gastroenterol Hepatol. 2006; 21:963-9. | Article | PubMed

9. Rodriguez-Ramos C, Galan F, Diaz F, Elvira J, Martin-Herrera L and Giron-Gonzalez JA. Expression of proinflammatory cytokines and their inhibitors during the course of spontaneous bacterial peritonitis. Dig Dis Sci. 2001; 46:1668-76. I Article I PubMed

10. Ambrosino G, Naso A, Feltracco P, Carraro P, Basso SM, Varotto S, Cillo U, Zanus G, Boccagni P, Brolese A, Plebani M, Giron G and D'Amico DF. Cytokines and liver failure: modification of TNF- and IL-6 in patients with acute on chronic liver decompensation treated with Molecular Adsorbent Recycling System (MARS). Acta Biomed. 2003; 74 Suppl 2:7-9. | Pdf | PubMed

11. Such J, Hillebrand DJ, Guarner C, Berk L, Zapater P, Westengard J, Peralta C, Soriano G, Pappas J and Runyon BA. Tumor necrosis factor-alpha, interleukin-6, and nitric oxide in sterile ascitic fluid and serum from patients with cirrhosis who subsequently develop ascitic fluid infection. Dig Dis Sci. 2001; 46:2360-6. I Article I PubMed

12. Sanchez-Rodriguez A, Criado M, Flores O, Olveira-Martin A, MartinOterino JA and Esteller A. Correlation of high levels of hyaluronan and cytokines (IL-1beta, IL-6, and TGF-beta) in ascitic fluid of cirrhotic patients. Dig Dis Sci. 2000; 45:2229-32. I PubMed

13. Souza MH, Cunha FQ and Martinelli AL. Interleukin 6 concentration in ascitic fluid of cirrhotic patients: relationship with previous episodes of spontaneous bacterial peritonitis. J Gastroenterol. 2003; 38:149-52. | Article | PubMed

14. Bac DJ, Pruimboom WM, Mulder PG, Zijlstra FJ and Wilson JH. High interleukin- 6 production within the peritoneal cavity in decompensated cirrhosis and malignancy-related ascites. Liver. 1995; 15:265-70. | Article | PubMed

15. Wang SS, Lee FY, Chan CC, Lu RH, Chao Y, Lin HC, Wu SL, Tsai YT and Lee $\mathrm{SD}$. Sequential changes in plasma cytokine and endotoxin levels in cirrhotic patients with bacterial infection. Clin Sci (Lond). 2000; 98:41925. | Article | PubMed

16. Lee FY, Lu RH, Tsai YT, Lin HC, Hou MC, Li CP, Liao TM, Lin LF, Wang SS and Lee SD. Plasma interleukin-6 levels in patients with cirrhosis. Relationship to endotoxemia, tumor necrosis factor-alpha, and hyperdynamic circulation. Scand J Gastroenterol. 1996; 31:500-5. | Article | PubMed

17. Odeh M, Sabo E, Srugo I and Oliven A. Serum levels of tumor necrosis factor-alpha correlate with severity of hepatic encephalopathy due to chronic liver failure. Liver Int. 2004; 24:110-6. | Article | PubMed

18. Zhang $L J$ and Wang XZ. Interleukin-10 and chronic liver disease. World J Gastroenterol. 2006; 12:1681-5. | Article | PubMed

19. Park MI et. al. "Tumor necrosis Factor-a and Interleukin- in ascitic fluid and plasma in spontaneous bacterial peritonitis.". Korean J. Hepatology. 1999; 5:314-321. | Article

20. Blackburn SD and Wherry EJ. IL-10, T cell exhaustion and viral persistence. Trends Microbiol. 2007; 15:143-6. | Article I PubMed

\section{Citation:}

Lagadinou M, Solomou EE, Mouzaki A and Gogos CA. Alterations in cytokine measurements in ascitic fluid of cirrhotic patients with and without spontaneous bacterial peritonitis. Clin Hepatol Hepat Rep. 2014; 1:1. http://dx.doi.org/10.7243/2055-088X-1-1 